\title{
Article
}

\section{Disaster Risk Reduction Compliance Framework for Public Private Partnership (PPP) Port Projects}

Liyanage, Champika Lasanthi and Villalba-Romero, Felix Available at http://clok.uclan.ac.uk/35740/

Liyanage, Champika Lasanthi ORCID: 0000-0001-6687-3611 and VillalbaRomero, Felix (2020) Disaster Risk Reduction Compliance Framework for Public Private Partnership (PPP) Port Projects. International Journal of Disaster Resilience in the Built Environment . ISSN 1759-5908

It is advisable to refer to the publisher's version if you intend to cite from the work. http://dx.doi.org/10.1108/JDRBE-05-2020-0053

For more information about UCLan's research in this area go to http://www.uclan.ac.uk/researchgroups/ and search for <name of research Group>.

For information about Research generally at UCLan please go to http://www.uclan.ac.uk/research/

All outputs in CLoK are protected by Intellectual Property Rights law, including Copyright law. Copyright, IPR and Moral Rights for the works on this site are retained by the individual authors and/or other copyright owners. Terms and conditions for use of this material are defined in the policies page.

\section{CLoK}

Central Lancashire online Knowledge www.clok.uclan.ac.uk

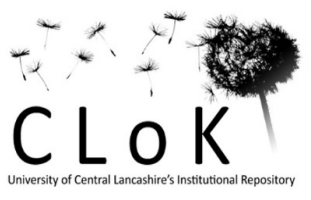




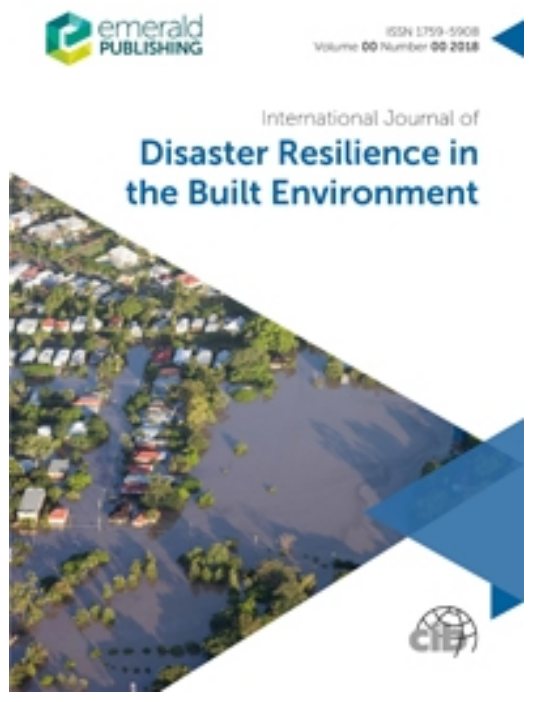

\section{Disaster Risk Reduction Compliance Framework for Public Private Partnership (PPP) Port Projects}

\begin{tabular}{|r|l|}
\hline Journal: & International Journal of Disaster Resilience in the Built Environment \\
\hline Manuscript ID & IJDRBE-05-2020-0053.R2 \\
\hline Manuscript Type: & Research Paper \\
\hline Keywords: & $\begin{array}{l}\text { Ports, Public Private Partnerships, Resilience, Disaster mitigation, Risk } \\
\text { reduction, Resilience framework }\end{array}$ \\
\hline \multicolumn{2}{|l}{} \\
\hline
\end{tabular}

\section{SCHOLARONE ${ }^{\text {M }}$ \\ Manuscripts}




\title{
Disaster Risk Reduction Compliance Framework for PPP (Public Private Partnership) Port Projects
}

\begin{abstract}
Purpose: The paper aims to identify success factors and resilience measures that contribute to Disaster Risk Reduction (DRR) in Public Private Partnerships (PPP) port projects in Asia. Significant losses have been associated with large-scale natural hazards, such as earthquakes, tsunami, cyclones, and other extreme weather events and thus, ports need to evaluate their resilience level and adopt relevant DRR strategies to improve it.

Methodology: A Step-by-step methodology, based on literature review, port cases analysis, questionnaire survey and expert opinions, was followed.

Findings: The paper provides a research instrument extracted from a large list of measures and factors after a combined screening process was carried out. This instrument offer policy makers and researchers a tool applicable to PPP port projects in Asian countries to evaluate the level of resilience.
\end{abstract}

Limitations: Relevant resilience measures for some specific projects may have not been considered in order to obtain a standardised instrument.

Originality /value: This paper fulfils an identified need to evaluate resilient port infrastructures and the output is a resilience framework to be used in PPP port projects in Asia.

Keywords: Disaster Mitigation; Ports; Public Private Partnerships; Resilience framework; Risk Reduction.

\section{INTRODUCTION}

The importance of port infrastructure in countries with large coastal areas is determined by its link with economic and social development. On the one hand, many traditional tasks have been developed around economic activities such as fishing and commercial exchange; and on the other hand, the port areas constitute bases and hubs of integrated multimodal transport, both nationally and internationally, from which other transport infrastructures have been extended. Moreover, many of these areas open to the sea are exposed to various risks of natural disasters that make them vulnerable from an economic and social point of view. As a result, ports need to adopt suitable Disaster Risk Reduction (DRR) strategies to reduce the impact of disasters on ports, port cities and neighbouring communities/businesses. The term Disaster Risk Reduction (DRR) refers to the "concept and practice of reducing disaster risks through systematic efforts in order to analyse and manage the causal factors of disasters" (UNISDR, 2009). DRR is a response to the challenges of climate change and there are some relevant works carried out with regard to DRR in ports, e.g. Cutter \& Director (2008), on Port resilience strategy and "Ports \& Planning for Resilience" by Mississippi-Alabama Sea Grant Consortium (n.d.). However, there is a clear gap in research in the area of DRR in PPP (Public Private Partnership) port projects, especially in the context of Asia. This paper attempts to fill this gap in knowledge. The paper starts with an introduction to 
port components and the importance of PPP port projects. It then details the methodology adopted and finally presents the findings from different data collection methods. Finally, a DRR compliance framework for PPP port projects is presented.

\section{Port components, resilience standards, and regulation}

A port is a harbour space or coastal area which provides shelter to boats and vessels and allows periodic shipment transactions, serving as a hub for social and economic activities, thereby facilitating commercial trade. Thus, ports require appropriate and complex facilities, well-equipped with specialised fixtures. They must be permanently open and available for operations. Common port facilities include port receptions; special warehouses for storing the shipments and regular stocks; loading and unloading facilities; and specific infrastructure. This infrastructure can include piers, basins, storage areas, general warehouses, and workshops for vessels. Most importantly there will be essential equipment, like hauling tools, cranes, and trucks, as well as specialised staff such as stevedores. Other facilities, namely business centres, hotels, restaurants, restrooms, primary medical services and other specific facilities vary according to the purpose and type of port, e.g. seaports of different categories (cargo or cruise); fishing ports, which require special hangers or trade premises; inland ports; dry ports; etc. Ports are strategic locations, usually situated at the edge of rivers, lakes, or seas, which often require overland and air access and connections, and intermodal transport nodes and access. Most ports should be considered as critical infrastructure by the authorities, demanding specific vulnerability assessment (Cheng-Hsien Hsieh et al., 2014), and are in need of a holistic resilience framework (Nair et al., 2010). They are subject to special treatment and regulation for safety and security reasons as ruled, within a European context, by the Council Directive 2008/114/EC of 8 December 2008. This directive concerns the identification and designation of European critical infrastructures, and assessment of the improvements required to assure their protection (̌̌ehák et al., 2016). Additional terms to be considered may be derived from the ISO/DIS 22316 on security and resilience. This standard provides guidelines for organisational resilience in three areas: principles, attributes, and activities that guide utilisation, evaluation, and improvements.

\section{Public Private Partnerships (PPPs) in ports}

Though traditionally port infrastructures have been served and operated by the public sector, the Public Private Partnership (PPP) approaches provide an efficient mechanism for the construction and operation of large-scale, complex projects, which may generate additional value for money and also have a key role in funding and financing (HM Treasury, 2003), (NAO, 2009). There are many studies showing the important role PPP plays in the management of disaster risks. For example, the Sendai Framework advocates that the leadership, regulation and coordination are the government's responsibility, in addition to communicating with all the people involved in the design and implementation of policies, plans, and regulations. The public and private sectors, civil society organisations and academic institutions should work more closely together, create opportunities for collaboration, and integrate disaster risks into businesses' management practices (UNISDR 2015). In addition to the Sendai Framework, PPP is also recommended by the Brazilian Civil Defence Act (Brazil, Law no. 12.608/12), and there is also motivation for the internationalisation of Corporate Social Responsibility (CSR). The discussion about PPP is becoming even more important because disaster statistics show an increase in frequency and intensity. This is a worrying trend for organisations involved as these events endanger not only lives, 
subsistence, and health, but also threaten the economic, physical, social, cultural and environmental assets of people, communities, companies and countries (Eyerkaufer et al., 2016). For DRR actions to be carried out efficiently in ports, Chen et al. (2018) suggest strategic investment in ports to reduce the vulnerability of the above. Disaster Risk Financing (DRF) is an investment strategy that can be adopted for this. DRF can be used to improve the long-term resilience of a port and to cover the direct and indirect economic losses incurred by stakeholders and society as a whole, in the aftermath of a disaster. Furthermore, long-term contract lifetimes of PPPs (averaging close to 30 years) increase the likelihood of a project being impacted by an adverse event and require a long-term commitment to measures that will support project sustainability (Baxter, 2018). Thus, as Baxter proposes, it is time for governments and private sector partners to acknowledge that measures that can be collaboratively undertaken to improve the resiliency of infrastructure projects, including ports, benefit all parties. As pointed out by the International Sustainable Resilience Center (ISRC) (Baxter, 2018), there are four aspects of resilience (4R practices) that should be considered in a project: robustness to withstand external demand, redundancy for system processes, resourcefulness for emergencies, and rapidity to restore operations. In a typical Design Built Finance Operate Maintain (DBFOM) PPP model, DRR 4R practices can be focussed on at all stages including planning, due diligence, transactional, and operation and maintenance (O\&M) stages, whilst in other PPP models, e.g. Design Build and Finance (DBF), O\&M are often consciously or subconsciously disregarded by project proponents. This is because O\&M concerns can fall into the future realm of project stakeholders' limited perceptions of predictable future risk, which can be clouded by intangible unpredictability and vague threat (Baxter 2018). Therefore, it is essential to develop proactive strategies that incorporate elements of holistic and comprehensive resilience best practices into the design, construction, financing, and operations and maintenance of all PPP port projects.

The predominant role taken by the public sector and its private partners is often not enough to deal with all the emergency actions required after a natural disaster takes place. The contribution made by people, alongside the partnership, should not be overlooked: individuals, local community entities and associations, and nongovernmental organisations (NGOs) often play a critical role. For it is not only the infrastructure assets that must be recovered during the postdisaster phase, but the disrupted lives of people (Hwang et al., 2015). Thus, people - as end users of the reconstructed infrastructure, who have valuable knowledge of the area and its needs become critical reference sources in the reconstruction process. They must actively participate in both postdisaster short-term actions - such as rescue, emergency planning, and operations restoration; and long-term activities working towards the reconstruction and recovery in a PPP project (Kumaraswamy et al., 2015).

\section{METHODOLOGY}

This paper is based on a 3-year EU-funded ERASMUS+ project entitled CABARET - Capacity Building in Asia for Resilience Education (2016-2019), in collaboration with Sri Lanka, Indonesia, the Maldives, Myanmar and the Philippines. The main purpose of the paper is to identify various resilience measures that may affect PPP ports. The concept of resilience to natural disasters has been extended recently to an increasing number of fields, mostly focussed around two aspects: economic and social resilience. Yet, Klein et al. (2003) discuss the use of the notion of adaptative capacity, using weather-related hazards in coastal megacities. Rose (2007) develops the 
economic side of resilience and distinguishes between static (existing resources) and dynamic resilience (reconstruction of the capital stock). A review of resilience literature in its widest context was carried out by Bhamra et al. (2010), looking at interfaces between organisational and infrastructural resilience. Berkes and Ross (2013) focus on community resilience and refer to an integrated approach, which includes multidisciplinary perspectives, such as social-ecological systems and the psychology of development and mental health. This identifies resilience as a systems concept and emphasises identifying and developing community strengths, and building resilience through agency and self-organisation.

Measuring resilience to natural disasters has been analysed from a variety of perspectives in communities, not only from the economic and direct impact of hazards, but by different models focussing at the local or community level (Cutter et al., 2008), and a number of metrics have been developed from sound case studies such as Hurricane Katrina (Burton, 2015). There are other interesting pieces of research which measure different aspects of port resilience, such as consequences of a port shutdown using an input-output analysis (Rose and Wei, 2013); or seismic resilience of seaports in a case study, which developed metrics to assess performance resilience measures in an infrastructure system (Shafieezadeh and Burden, 2014).

For the purpose of this research, the starting point for developing measures was the identification of coastal resilience indicators, based on the extensive literature review carried out as part of the CABARET Project work. The purpose of the literature review was to identify resilience indicators that are applicable for port infrastructures. The detailed findings of the literature review have been presented at the International Conference on Building Resilience - ICBR 2018 in Lisbon, Portugal (Villalba-Romero and Liyanage, 2018).

As part of the methodology, pilot case studies were conducted in the CABARET Asian countries (Port of Colombo - Sri Lanka; Makassar New Port, in South Sulawesi, Bitung International in North Sulawesi, Maloy Port in East Kalimantan - Indonesia) and countries that had similar experiences (i.e. negative impacts) of coastal hazards. The pilot case studies were conducted in some of the CABARET Asian countries, and also additional cases were considered from other geographical areas for comparison and validation. The choice of additional case studies was based on the level of the impact of hazards on ports, and on the availability of data from PPP Port projects on resilience measures. Reviewing pilot cases was important to understand common components of the ports' facilities, operations and business models, and especially to find out relevant elements of vulnerability and resilience needs.

After considering diverse geographical zones, European ports were not included due to the low level of hazards within this area. Special attention was given to the Pacific area of Latin America, where a Chilean Port, the Port of Iquique, was looked at in detail. Some case studies from the USA were also used, based on the report "Ports \& Planning for Resilience" (Mississippi-Alabama Sea Grant Consortium, USA, (IRG)):

- Port of Corpus Christi - Texas

- Port of Lake Charles - Louisiana

- Port of Pascagoula - Mississippi

After reviewing the resilience indicators extracted from the literature review and analysing the pilot case studies, the port-related list of resilience indicators was categorised into:

I) Planning for Hazards and Threats, 
II) Hazard Assessment: Infrastructure and Assets,

III) Insurance and Risk Management,

IV) Continuity of Operations Planning for Infrastructure and Facilities,

V) Critical Records and Administration,

VI) Community Restoration, and

VII) Emergency Plans.

A questionnaire was subsequently developed based on the synthesis of the literature review and pilot case study findings. The questionnaire was distributed to all CABARET project partners during a main project meeting conducted in Manila, Philippines in March 2019. This was a multidisciplinary group of experts in the areas of disaster/coastal resilience and infrastructure projects. The objective of the survey was to assess the importance of resilience indicators and measures, especially in the Asian context; but comparisons were also made from the EU perspective. Several country groups were created during the project meeting (about 40 partners attended the meeting). In total 8 country groups were formed, of which 5 groups were from the Asian countries: Maldives, Philippines, Myanmar, Sri Lanka and Indonesia; and the 3 other groups were from the UK, Bulgaria and Latvia. Each group was presented with the same questionnaire, and they were asked to discuss and brainstorm in groups, for instance, the importance of resilience measures in the context of their country. The significant feature of the survey method was that it was not filled in individually but collectively, as a group, by achieving consensus among the group. The groups were all given about $1 \frac{1}{2}$ hours to 2 hours to complete the questionnaire.

The content of the survey included a mix of open and closed questions that were evaluated with a Likert scale. In total, the questionnaire contained 61 items, which correspond to resilience measures (RM), grouped in 15 main questions. The initial questions were to identify the country of the working group, etc. The principle closed question was to assess the importance of resilience indicators and measures. This was given as a 5-point Likert scale question (1- Very important, 2- Fairly important, 3Important, 4- Slightly important, 5- Not at all important). The question was categorised into sub-sections based on the seven indicators mentioned above, which were previously identified as critical factors: Planning for Hazards and Threats; Hazard Assessment: Infrastructure and Assets; Insurance and Risk Management; Continuity of Operations Planning for Infrastructure and Facilities; Emergency Plans; Critical Records and Administration; and Community Restoration. As for questions 3, 5, 7, 9, 11,13 and 15, they consisted of open questions with the objective of identifying new resilience measures in each category.

The rest were closed questions, which focussed on specific resilience measures in each of the selected categories, except for one question that related to factors. These questions inquired about the importance of specific measures (number indicated in brackets) in each category, questions 4 (9), 6 (6), 8 (9), 10 (7), 12 (7) and 14 (7). These do not include the Emergency Plan category, for which no measures were included. For each question, these items were presented as sub-questions to be answered within a Likert scale of 1 to 4 (1- Very important, 2- Important, 3- Slightly important, 4- Not at all important). In addition, there was a general open final question with the aim of gathering other comments on Port Resilient Measures.

Therefore, the original questionnaire included: $\underline{1}$ discriminative question selecting the country's team; $\underline{\mathbf{8}}$ questions on the 7 categories of critical resilience factors (i.e. 7 sub-questions on these factors and 1 open question for possible additional factors); and $\underline{51}$ questions on specific measures within each category (45 closed sub-questions - 9, 6, 
9, 7, 7, 7 measures for each factor respectively; and 6 open questions). With the inclusion of $\underline{\mathbf{1}}$ final general open question, this makes a total of $\underline{\mathbf{6 1}}$ specific questions.

\section{Results}

All questions were derived and justified from the literature review and interviews reflecting general agreements. In addition to the defined, closed questions, the questionnaire was designed as another opportunity to consider new emerging resilience measures, including open questions to explore relevant measures that may not have been included. However, the questionnaires focussed primarily on the closed questions. Therefore, the purpose of the final survey was not just to identify whether the respondents considered those questions important or not, but to assess the exact level of importance of each question to achieve consensus in the screening process of the Port Resilience Measures.

For the closed questions, the statistical data are the mean, standard deviation and one sample t-test (compared with the "3- Slightly important" value, since the "4-Not at all important" value, was not considered due to the low probability of it being selected).

The results offered in Annex 1 only show a selected list of measures that achieved the highest consensus among the participants. It also presents the level of importance or criticality of each resilience factor and measure, ordered by national teams, and include the following statistical data for All answers: means, standard deviation and t-test. Additional mean data columns grouped by continents (Asia and Europe) are included. The selected resilience factors and measures are ranked by All answer Mean.

From a first glance at the results, it seems rather clear that many answers are marked with 1 in the Likert scale, which means the selected resilience success factor and measures achieve the highest score being "Very important". There are some answers marked with 2, meaning "Fairly important" or "Important" for factors and measures respectively; and just a few answers marked with 3, meaning "Important" or "Slightly important" also respectively for factors and measures. No answers obtain a score of 4 or less.

The results in the aforementioned annex 1 show how measure Availability of a hazard or emergency preparedness plan, generates maximum consensus (scoring a clear 1), since absolutely all the participants considered it a "Very important" resilience factor, however no specific measure was suggested or identified as "Important" in this area. Other items ranking within the highest score (1.11 All mean) are factor Planning for hazard and threats, and measures Availability of a plan/protocol to establish emergency reactivation of utilities and services after an event; and Identification of risks to the communities from potential hazards, during their regular assessment of risks to the critical infrastructure and services. The mean is gradually increasing for the rest of the selected measures and factors to a maximum of 1.5, which is the cut-off level for the selection. The rest of the factors that are above the cut-off level were discarded with the only exception of factor Community Restoration, as explained in the next section of screening measures.

With regard to the open questions, the results are diverse and dispersed. As a initial conclusion, they show different concerns in the European team answers from those of the Asian teams, clearly more sensitive to the higher devastating effects of hazards in its geographical area. For this reason, it was decided to focus mainly on the Asian teams' answers to explore potential emerging measures. In general, there was no new reiterative resilience measure identified, that was suggested by more than one team. Instead, the questionnaire answers mostly raised relevant issues related to general actions on disaster risk reduction (External support, Capacity development; 
Rehabilitation plan; Health care and Psychological support) or completed the content of some of the already identified resilience measures (Regular Risk Assessment for Hazards; Insurance alignment with investment budget; Insurance alignment with types of goods). Other answers mentioned elements which were interesting, but too specific to be considered for a limited questionnaire (i.e. In-house stock-pile for workers and community, Inclusion of man-made hazards such as oil spills; or Back-up of the LAN WAN).

By categories and teams, most comments referred to the factor "Planning for Hazards and Threats". These included concern for risk assessment -by the Maldives team; hazards records and maps -by the Myanmar team; forecasting climate change and communication of the results, as well as the alignment national guidelines/framework by the Philippines team; and in general, Disaster Resilience Infrastructure -by the Sri Lanka team. Other areas which received any interesting suggestions were "Insurance and risk management", showing concern about specific coverage for damages caused by vessels/ships -by the Philippines team; health or environment, the sharing of responsibilities, or insurance alignments -by the Philippines team. Comments also draw attention to the area of "Continuity of Operation Planning for Infrastructure and Facilities", such as resilience of alternative transportation routes - by the Maldives team; diverse evacuation plan for hazard or rehabilitation plans - by the Philippines team; and extreme and climate change contingencies -by the Indonesian team. More detailed information may be analysed in the summarised table included in Annex 2.

In summary, the open answers brought interesting comments and suggestions for an exhaustive analysis. However none of the proposed resilience measures are clearly repeated across the different national teams.

\section{SCREENING MEASURES}

Having analysed the results of the first survey and having decided not to expand the research instrument - neither with new resilience factors or areas, nor with additional resilience measures - the next step was to conduct a screening process based on firstly, the results of the questionnaire and secondly, the contrast with expert opinions in a second round.

In order to do the first screening based on the importance or criticality level of the survey results, all of the resilience measures were ranked in a descending order according to the obtained answers, as shown in Annex 1.

Any All Mean value in the range 1-1.5 shows how the majority of the participants consider the RM is very important. Therefore, an average value below 1.5, the cut-off value, is considered the threshold for a second screening process and all RM with average of 1.5 or above are discarded.

The second questionnaire was prepared to discuss with experts a selected number of measures, based on those factors and measures which achieved an All Mean lower than 1.5. Thus, 20 measures and 1 factor (Community restoration) were discarded for the second round, as well as the open question on factors. As a consequence, the second questionnaire includes: 1 country identification question, 6 questions on factors, 31 questions on measures (of which 25 closed and 6 open questions) and the final 1, making a total of 39 remaining items for the second-round refinement.

The second round took place through interviews with expert practitioners in Ports who had experience advising Port authorities in resilience success factors and measures. This exercise was an effective qualitative comparative method to link and contrast the 
views from expert researchers with expert practitioners in Port resilience. It is worth noting that the main differences were based on the level of criticality rather than on the appropriateness of the factors and measures. In this regard, the one factor discarded in the first round, "Community restoration", was recovered after being slightly nuanced to "Community support". Two of the selected measures: Risk identification to the communities linked to the infrastructure and services, and Communication plans to engage the communities in hazard awareness, fell under this factor category. As for the "Planning for hazards and threats" factor, the resilience measures analysed were condensed to: the availability of a hazard/emergency preparedness plan and the integration of this plan into local/national response and recovery plans. The rest of the measures were discarded considering their lower criticality. There were some discussions within this factor identifying specific building measures (such as breakwater, walls and related protection methods) to further protect the infrastructure from hazard; however, those measures were not generally applicable to all ports and therefore were not finally included for consideration because they were extremely costly and difficult to justify on resilience grounds alone.

Similarly, for the factor "Hazard assessment: Infrastructure and Assets" most essential measures were identified as related to the condition of the facilities to ensure the proper maintenance and safety, since there is no systematic approach to hazard assessment, partly because of the lack of any clear methodology.

A single measure remained in the area of "Insurance and risk management", which summarises the most important element: a plan to cover aid in global terms for emergency support; for instance in the prioritisation of the critical facilities and services to be restored. Specific measures may depend on the port structure, whether it has or not a clear separation of responsibility for infrastructure and operations (i.e. landlord port and cargo handling company).

Crucial measures screened for "Continuity of operations" consisted of the availability of: reactivation plans for the utilities and services; identified supplier information for emergency response; master services agreements for emergency response and restorations which affect the port. Continuity has been provided by a succession of strong, experienced, and independent Harbour Masters - the key figure in a port's emergency response plans.

Additional key measures in "Critical Records and Administration" are service contracts to store critical records as well as offsite storage for electronic data - measures which clearly are vital for the service restoration. A port authority usually maintains few written records of the damage caused by the hazards, and a lack of formal procedures for damage mapping or costing is common. Thus, the proposed measures are justified.

The "Emergency plan" factor may greatly affect an outcome, but no specific measures are considered in the final research instruments, other than those measures already commented on, related to other factors. Of critical importance is whether any emergency plan is available, as these are often developed internally according to the standard of the facilities.

The open questions again raised new suggestions regarding coordination, prioritisation and information dissemination; these are interesting in general terms, however, not to be presented as new resilience measures. Therefore, it was decided not to include additional resilience measures in the refined research instrument 


\section{RESEARCH INSTRUMENT PROPOSAL}

The two-round screening process yielded the following results: the selection of 7 questions regarding the original resilience factors, and 13 questions on the implementation of resilience measures, to produce a summarised final research instrument. This research instrument is the output tool for analysing the Resilience compliance for PPP Port projects, as presented in Table 1.

This tool becomes an effective and simple instrument to be applied to a port case study to easily evaluate at which point a port is compliant with a Resilience framework. 


\section{Insert Table 1}


The current work has developed a Resilience Framework to evaluate the compliance of a PPP Port with identified critical factor and resilience measures. To develop this framework a number of research activities have been carried out. Firstly, gathering resilience knowledge in PPP Ports from pilot case studies and a literature review; secondly, developing a questionnaire which has been answered by national multidisciplinary teams which are participants in the CABARET project; and finally the results have been refined with the opinion of independent expert practitioners who conduct consultancy activities in this field. As a consequence, this research has produced a refined instrument for Resilience Compliance which may be used for evaluating the resilience level of PPP Ports. The results show how assessment of the resilience of PPP Ports is summarised in the evaluation of the 7 identified main critical success factors and the 13 key resilience measures. Further research is required to complement the robust resilience framework, which could be incorporated into a holistic public decision model.

The way forward is to apply this research instrument to a number of selected case studies. This would analyse its effectiveness and enable validation of the model. The obtained resilience index could be applicable to a range of port projects which have followed some PPP modality. Within the CABARET project it may be applied to projects in the 5 participating Asian countries and the results will contribute extensively towards calibrating the mentioned holistic model.

\section{REFERENCES}

Baxter, David (2018). How Resilient Are Your PPP Projects To Adverse Natural Events? International Sustainable Resilience Centre (ISRC). https://ippprc.org/knowledgesharing (last access dated 05-08-20)

Berkes F. \& Ross H. (2013) Community Resilience: Toward an Integrated Approach, Society \& Natural Resources, 26:1, 5-20, DOI: $10.1080 / 08941920.2012 .736605$

Bhamra, R., Dani S., \& Burnard K. (2011) Resilience: the concept, a literature review and future directions, International Journal of Production Research, 49:18, 5375-5393, DOI: 10.1080/00207543.2011.563826

Brazil, Law No. 12.608 (2012) Establishing the PNPDEC: It provides for the SINPDEC and CONPDEC; authorizes the creation of information system and disaster monitoring, Brasília, DF.

Brooks, M. R., \& Pallis, A. A. (2008). Assessing port governance models: process and performance components. Maritime Policy \& Management, 35(4), 411-432.

Burton C. (2015) A Validation of Metrics for Community Resilience to Natural Hazards and Disasters Using the Recovery from Hurricane Katrina as a Case Study, Annals of the Association of American Geographers, 105:1, 67-86, DOI: $10.1080 / 00045608.2014 .960039$

Busch, N. E., \& Givens, A. D. (2013). Achieving resilience in disaster management: the role of public-private partnerships. Journal of strategic security, 6(2), 1-19.

Cheng-Hsien Hsieh, Hui-Huang Tai \& Yang-Ning Lee (2014) Port vulnerability assessment from the perspective of critical infrastructure interdependency, Maritime Policy \& Management, 41:6, 589-606, DOI: $10.1080 / 03088839.2013 .856523$

Chen, H., Lam, J. S. L., \& Liu, N. (2018). Strategic investment in enhancing port-hinterland container transportation network resilience: A network game theory approach. Transportation Research Part B: Methodological, 111, 83-112.

Clarke, D., De Janvry, A., Sadoulet, E., Skofias, E. (2015a) Disaster Risk Financing and Insurance: Issues and results. ferdi.fr / World Bank 
Clarke, D, Mahul, O., Poulter, R., \& Teh, T.L. (2015b) FERDI-WB Disaster Risk Financing and Insurance Policy Brief

Cutter, S. L., \& Director, H. (2008). A framework for measuring coastal hazard resilience in New Jersey communities. White Paper for the Urban Coast Institute.

Cutter, S. L., Barnes, L., Berry, M., Burton, C., Evans, E., Tate, E., \& Webb, J. (2008). A place-based model for understanding community resilience to natural disasters. Global environmental change, 18(4), 598-606.

Eyerkaufer, M. L., Lima, F. S., \& Gonçalves, M. B. (2016). Public and private partnership in disaster risk management. Jàmbá: Journal of Disaster Risk Studies, 8(1).

Hwang, S., Park, M. Lee, H.-S., Lee, S.-H. and Kim, H. (2015), "Postdisaster interdependent built environment recovery efforts and the effects of governmental plans: case analysis using system dynamics", Journal of Construction Engineering and Management, Vol. 141 No. 3, p. 04014081, available at: http://dx.doi.org/10.1061/(ASCE)CO.1943-786 2.0000939

HM Treasury (2003), PFI: Meeting the Investment Challenge, HMSO, Norwich, p. 43.

Klein, R., Nicholls R. \& Thomalla F. (2003) Resilience to natural hazards: How useful is this concept?, Global Environmental Change Part B: Environmental Hazards, 5:1, 35-45, DOI: 10.1016/j.hazards.2004.02.001

Kumaraswamy, M. M., Zou, W. W. and Zhang, J. Q. (2015), "Reinforcing relationships for resilience - by embedding end-user people' in public private partnerships", Journal of Engineering and Environmental Systems, Vol. 32 Nos 1/2, pp. 119-129. DOI: 10.1080/10286608.2015.1022727.

Mississippi-Alabama Sea Grant Consortium, USA (n.d.). Resilience Indices. Last access dated 05-05-20 http://masgc.org/coastal-storms-program/resilience-index

Nair, R., Avetisyan, H., \& Miller-Hooks, E. (2010). Resilience framework for ports and other intermodal components. Transportation Research Record, 2166(1), 54-65.

National Audit Office (NAO) (2009), Performance of PFI Construction, NAO Marketing \& Communications Team, London

Řehák, D., Hromada, M., \& Novotný, P. (2016). European critical infrastructure risk and safety management: directive implementation in practice. In 15th International Symposium on Loss Prevention and Safety Promotion (LOSS 2016). Italian Association of Chemical Engineering (AIDIC)

Rose, A. (2007) Economic resilience to natural and man-made disasters: Multidisciplinary origins and contextual dimensions, Environmental Hazards, 7:4, 383-398, DOI: 10.1016/j.envhaz.2007.10.001

Rose A. \& Wei D. (2013) Estimating the Economic Consequences of a Port Shutdown: the Special Role of Resilience, Economic Systems Research, 25:2, 212-232, DOI: 10.1080/09535314.2012.731379

Sánchez, R. J., Hoffmann, J., Micco, A., Pizzolitto, G. V., Sgut, M., \& Wilmsmeier, G. (2003). Port efficiency and international trade: port efficiency as a determinant of maritime transport costs. Maritime economics \& logistics, 5(2), 199-218.

Shafieezadeh, A., \& Burden, L. I. (2014). Scenario-based resilience assessment framework for critical infrastructure systems: Case study for seismic resilience of seaports. Reliability Engineering \& System Safety, 132, 207-219 
Stewart, G.T., Kolluru, R. \& Smith, M., 2009, 'Leveraging public-private partnerships to improve community resilience in times of disaster', International Journal of Physical Distribution \& Logistics Management 39, $343-364$. http://dx.doi.org/10.1108/09600030910973724

United Nations, International Strategy for Disaster Reduction - UNISDR (2015) 'Sendai Framework for disaster risk reduction 2015 - 2030 A/CONF.224/CRP.1 gives Third World Conference', viewed 13 April 2015, from http://www.wcdrr.org/uploads/Sendai_Framework_for_Disaster_Risk_Reduction_2015-2030.pdf

United Nations, International Strategy for Disaster Reduction - UNISDR (2009) Terminology on Disaster Risk Reduction. https://www.unisdr.org.

Villalba-Romero, F., Liyanage, C. (2018). Building resilience to natural disasters using financial instruments. $8^{\text {th }}$ International Conference on Building Resilience (ICBR) in Mendez, J.M.: Investing in Disaster Risk Reduction for Resilience, November 14-16, 2018, Lisbon, Portugal. ISBN 978-989-20-8992-8 
Insert Annexl 


\section{Insert Annex 2}


Table 1: Final Research Instrument

No. Resilient Measures - Factors (Categories)

1 I. Planning for Hazards and Threats

2 II. Hazard Assessment: Infrastructure and Assets

3 III. Insurance and Risk Management

4 IV. Continuity of Operations Planning for Infrastructure and Facilities

5 V. Emergency Plans

6 VI. Community Support

7 VII. Critical Records and Administration I. PLANNING FOR HAZARDS AND THREATS - Measures

8 Availability of a hazard or emergency preparedness plan

9 Integration of the emergency response and contingency plans into local/national emergency response and recovery plans II. HAZARD ASSESSMENT: INFRASTRUCTURE AND ASSETS - Measures

10 Regular assessment of the condition of its facilities to identify maintenance issues requiring corrective action to increase safety?

11 Identification of information related to hazard risks and probabilities for future threats/hazards based on historic trends and past events (e.g., climatic data, weather records)

12 Identification of possible mitigation procedures to address future threats/hazards based on the information gathered above? III. INSURANCE AND RISK MANAGEMENT - Measures

13 Availability of a plan to provide or request mutual aid for emergency support operations (e.g. providing fuel for generators; water; medical transport services) IV. CONTINUITY OF OPERATIONS PLANNING FOR INFRASTRUCTURE AND FACILITIES Measures

14 Availability of a plan/protocol to establish emergency reactivation of utilities and services after an event?

15 Availability of list of supplier information to allow for quick scheduling of emergency response and recovery services (e.g., equipment, supplies, damage assessment, facility control)?

16 Availability of master service agreements by the local/national government for emergency response and restoration that could benefit the Port? V. CRITICAL RECORDS AND ADMINISTRATION - Measures

17 Availability of service contracts with an archival agency to store critical records

18 Implement offsite storage for electronic data (e.g. hard drive backup at offsite location, backup to the cloud)? VI. COMMUNITY SUPPORT - Measures

19 Identification of risks to the communities from potential hazards, during their regular assessment of risks to the critical infrastructure and services

20 Availability of communication plans/protocols to increase awareness of the communities from potential hazards OTHER PORT RESILIENCE MEASURE 


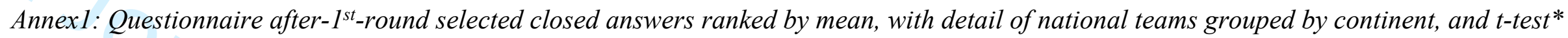

\begin{tabular}{|c|c|c|c|c|c|c|c|c|c|c|c|c|c|}
\hline Type & Item & Scale & Rank & $\begin{array}{l}\text { ASIA } \\
\text { Mean }\end{array}$ & MAL & PHI & IMYA & A SLK & IND & $\begin{array}{l}\text { EUR } \\
\text { Mean }\end{array}$ & $\begin{array}{l}\text { All } \\
\text { Mean }\end{array}$ & $\begin{array}{l}\text { All } \\
\text { SD }\end{array}$ & $t$-test $p$ \\
\hline M.H.Plan & Availability of a hazard or emergency preparedness plan & $1-4$ & 1 & 1 & 1 & 1 & 1 & 1 & 1 & & 1,00 & 0,00 & $\#_{i} \mathrm{DIV} / 0$ ! \\
\hline Factor & Planning for hazards and threats & $1-5$ & 2 & 1 & 1 & 1 & 1 & 1 & 1 & 1,25 & 1,11 & 0,31 & 0,00000 \\
\hline M.Cont.Op. & Availability of a plan/protocol to establish emergency reactivation of utilities and services after an event? & $1-4$ & 3 & 1 & 1 & 1 & 1 & 1 & 1 & 1,25 & 1,11 & 0,31 & 0,00000 \\
\hline M.Comm.S. & Identification of risks to the communities from potential hazards, during their regular assessment of risks to the critical infrastructure and services & $1-4$ & 4 & 1,2 & 1 & 1 & 1 & 1 & 2 & 1 & 1,11 & 0,31 & 0,00000 \\
\hline Factor & Insurance and Risk Management & $1-5$ & 5 & 1 & 1 & 1 & 1 & 1 & 1 & 1,5 & 1,22 & 0,42 & 0,00000 \\
\hline Factor & Continuity of operations planning for infrastructure and facilities & $1-5$ & 6 & 1 & 1 & 1 & 1 & 1 & 1 & 1,5 & 1,22 & 0,42 & 0,00000 \\
\hline M.H.Plan & Integration of the emergency response and contingency plans into local/national emergency response and recovery plans & $1-4$ & 7 & 1,2 & 1 & 1 & 1 & 1 & 2 & 1,25 & 1,22 & 0,42 & 0,00000 \\
\hline M.H.Assess & Regular assessments of critical infrastructure and facilities to identify potential hazards? & $1-4$ & 8 & 1,2 & 1 & 1 & 2 & 1 & 1 & 1,25 & 1,22 & 0,42 & 0,00000 \\
\hline M.Cont.Op. & $\begin{array}{l}\text { Availability of master service agreements by the local/national government for emergency response and restoration that could benefit the Port (e.g., } \\
\text { highwway cleaning equipment to clear debris from roads leading into and out of the port facility)? }\end{array}$ & $1-4$ & 9 & 1,4 & 3 & 1 & 1 & 1 & 1 & 1 & 1,22 & 0,63 & 0,00002 \\
\hline M.Comm.S. & Inclusion of community needs and vulnerabilities within the Port's evacuation and emergency response plans & $1-4$ & 10 & 1,2 & 1 & 1 & 1 & 2 & 1 & 1,25 & 1,22 & 0,42 & 0,00000 \\
\hline Factor & Emergency plans & $1-5$ & 11 & 1 & 1 & 1 & 1 & 1 & 1 & 1,75 & 1,33 & 0,67 & 0,00005 \\
\hline Factor & Critical Records and Administration & $1-5$ & 12 & 1,4 & 3 & 1 & 1 & 1 & 1 & 1,25 & 1,33 & 0,67 & 0,00005 \\
\hline M.H.Plan & $\begin{array}{l}\text { Prioritisation of critical facilities and services to be restored in order for the Port to resume normal operations (e.g. terminal equipment, storage } \\
\text { facilities) }\end{array}$ & $1-4$ & 13 & 1,4 & 1 & 1 & 2 & 2 & 1 & 1,25 & 1,33 & 0,47 & 0,00000 \\
\hline M.H.Plan & Availability of annual drills to prepare personnel and community for emergency situations & $1-4$ & 14 & 1,4 & 1 & 1 & 2 & 2 & 1 & 1,25 & 1,33 & 0,47 & 0,00000 \\
\hline M.H.Assess & Identification of possible mitigation procedures to address future threats/hazards based on the information gathered abo & $1-4$ & 15 & 1,4 & 1 & 1 & 2 & 1 & 2 & 1,25 & 1,33 & 0,47 & 0,00000 \\
\hline M.Ins\&Risk & $\begin{array}{l}\text { Port's emergency plan include notification to the Port's insurance broker and contracted respondents (e.g. vendors and consultants) to request an } \\
\text { adjuster when an event is in the forecast }\end{array}$ & $1-4$ & 16 & 1,4 & 1 & 1 & 2 & 2 & 1 & 1,25 & 1,33 & 0,47 & 0,00000 \\
\hline M.Ins\&Risk & Availability of an insurance/finance to cover costs incurred for emergency response and recovery efforts & $1-4$ & 17 & 1 & 1 & 1 & 1 & 1 & 1 & 1,75 & 1,33 & 0,47 & 0,00000 \\
\hline M.Cont.Op. & Availability of an offsite evacuation site or alternative operations location site, based on the type of event, where it can continue basic operations & $1-4$ & 18 & 1,2 & 1 & 1 & 1 & 2 & 1 & 1,5 & 1,33 & 0,67 & 0,00005 \\
\hline M.Rec.\&Ad. & Implement offsite storage for electronic data (e.g. hard drive backup at offsite location, backup to the cloud)? & $1-4$ & 19 & 1,2 & 1 & 1 & 2 & 1 & 1 & 1,5 & 1,33 & 0,47 & 0,00000 \\
\hline M.Comm.S. & Availability of plans provide assistance to the community in the event of a disaster (e.g., Navy Hospital Ships, FEMA/MARAD Ready Reserve Force) & $1-4$ & 20 & 1,2 & 1 & 1 & 1 & 2 & 1 & 1,5 & 1,33 & 0,47 & 0,00000 \\
\hline Factor & Hazard Assessment: infrastructure and assets & $1-5$ & 21 & 1,4 & 1 & 2 & 2 & 1 & 1 & 1,5 & 1,44 & 0,50 & 0,00001 \\
\hline M.H.Assess & Regular assessment of the condition of its facilities to identify maintenance issues & $1-4$ & 22 & 1,4 & 1 & 1 & 2 & 2 & 1 & 1,5 & 1,44 & 0,50 & 0,00001 \\
\hline M.H.Assess & Assessment to identify infrastructure and facility upgrades necessary to limit damages from potential hazards? & $1-4$ & 23 & 1,4 & 1 & 1 & 1 & 2 & 2 & 1,5 & 1,44 & 0,50 & 0,00001 \\
\hline M.H.Assess & $\begin{array}{l}\text { Identification of information related to hazard risks and probabilities for future threats/hazards based on historic trends and past events (e.g., climatic } \\
\text { data, weather records, incidents onsite, economic trends) }\end{array}$ & $1-4$ & 24 & 1,4 & 1 & 1 & 1 & 2 & 2 & 1,5 & 1,44 & 0,50 & 0,00001 \\
\hline M.Ins\&Risk & Determine acceptable level of risk (or risk tolerance) for various hazards & $1-4$ & 25 & 1,2 & 1 & 1 & 1 & 2 & 1 & 1,75 & 1,44 & 0,50 & 0,00001 \\
\hline M.Ins\&Risk & $\begin{array}{l}\text { Availability a plan to provide or request mutual aid for emergency support operations (e.g. providing fuel for generators; water; medical transport } \\
\text { services) }\end{array}$ & $1-4$ & 26 & 1,4 & 2 & 1 & 1 & 1 & 2 & 1,5 & 1,44 & 0,50 & 0,00001 \\
\hline M.Cont.Op. & $\begin{array}{l}\text { Availability of list of supplier information to allow for quick scheduling of emergency response and recovery services (e.g., equipment, supplies, } \\
\text { damage assessment, facility control, channel maintenance)? }\end{array}$ & $1-4$ & 27 & 1,4 & 2 & 1 & 1 & 2 & 1 & 1,5 & 1,44 & 0,50 & 0,00001 \\
\hline M.Cont.Op. & Routine maintenance checks throughout the year of the alternative operations location to ensure its readiness to respond to emergency situations & $1-4$ & 28 & 1,4 & 1 & 1 & 2 & 2 & 1 & 1,5 & 1,44 & 0,50 & 0,00001 \\
\hline M.Rec.\&Ad. & Availability of service contracts with an archival agency to store critical records & $1-4$ & 29 & 1,4 & 1 & 1 & 2 & 1 & 2 & 1,5 & 1,44 & 0,50 & 0,00001 \\
\hline M.Comm.S. & Availability of communication plans/protocols to increase awareness of the communities from potential hazards & $1-4$ & 30 & 1,6 & 3 & 1 & 1 & 2 & 1 & 1,25 & 1,44 & 0,68 & 0,00010 \\
\hline M.Comm.S. & Integration with the communities during the annual drills & $1-4$ & 31 & 1,8 & 2 & 1 & 2 & 2 & 2 & 1 & 1,44 & 0,50 & 0,00001 \\
\hline Factor & Community Support & $1-5$ & 32 & 1,8 & 2 & 2 & 2 & 1 & 2 & 1,25 & 1,56 & 0,50 & 0,00002 \\
\hline
\end{tabular}

* Scale-Likert scale; Rank; MAL-Malaysia, PHI-Philippines; MYA-Myanmar; SLK-Sri Lanka; IND-Indonesia; Asia Mean; EUR (Europe) Mean; All Teams Mean; All Standard Deviation Team 
Annex 2: Open question and answers from Asian countries

\begin{tabular}{|c|c|c|}
\hline & Open Questions / Answers & \\
\hline 3 & $\begin{array}{l}\text { RESILIENCE MEASURE CATEGORY. What other category/ies do you think is/are missing } \\
\text { from the above list given in Question 1? } \\
\text {-Availability of utilities/lifeline, human resources; } \\
\text {-External support, capacity development; } \\
\text {-Impact Assessment (Pre and Post); Social safe guard; } \\
\text {-Vulnerability assessment of hinterland; Trained of port personnel; }\end{array}$ & $\begin{array}{l}\text { Philippines } \\
\text { Myanmar } \\
\text { Sri Lanka } \\
\text { Indonesia }\end{array}$ \\
\hline 5 & $\begin{array}{l}\text { PLANNING FOR HAZARDS. What other measures do you think are missing from the above } \\
\text { list of 'Planning for Hazards'? } \\
\text {-Regular Risk Assessments for Hazards; } \\
\text {-Forecasting given climate change, sea level rise, and land subsidence; Alignment with } \\
\text { national guidelines/framework; Availability of hazard maps; Inclusion of man-made } \\
\text { hazards such as oil spills, etc.; Communication of results hazards assessment to relevant } \\
\text { stakeholders. } \\
\text {-Previous hazard record; Hazard zonation mapping; vulnerability measures; Safety plan for } \\
\text { workers/community (eg. safety handbook; material, training); } \\
\text {-Disaster Resilient Infrastructure; }\end{array}$ & $\begin{array}{l}\text { Maldives } \\
\text { Philippines } \\
\text { Myanmar } \\
\text { Sri Lanka }\end{array}$ \\
\hline 7 & $\begin{array}{l}\text { HAZARD ASSESSMENT: INFRASTRUCTURE AND ASSETS. What other measures do you } \\
\text { think are missing from the above list of 'Hazard Assessment'? } \\
\text {-Communication of results of hazard assessment to relevant stakeholders; } \\
\text {-Consideration on community; cultural; Hazard assessment mapping in align with types of } \\
\text { the hazard } \\
\text {-Depend on site specific requirements; }\end{array}$ & $\begin{array}{l}\text { Philippines } \\
\text { Myanmar } \\
\text { Indonesia }\end{array}$ \\
\hline 9 & $\begin{array}{l}\text { INSURANCE AND RISK MANAGEMENT. What other measures do you think are missing } \\
\text { from the above list of 'Insurance and Risk Management'? } \\
\text {-Clear accountability and insurance coverage for damages caused by specific vessels/ships; } \\
\text {-Insurance index map; Safety, health and environmental assessment; Responsibility shared } \\
\text { with port authority and ownership; Insurance align with investment budget: insurance align } \\
\text { with types of goods }\end{array}$ & $\begin{array}{l}\text { Philippines } \\
\text { Myanmar }\end{array}$ \\
\hline 11 & $\begin{array}{l}\text { CONTINUITY OF OPERATIONS PLANNING FOR INFRASTRUCTURE AND } \\
\text { FACILITIES. What other measures do you think are missing from the above list of } \\
\text { 'Continuity of Operations' } \\
\text {-Resilience of alternative transportation routes; } \\
\text {-Drill for the workers and community to response the disaster; Evacuation plan for different } \\
\text { types of disaster; In-house stock-pile for workers and community; Rehabilitation; } \\
\text {-Extreme climate; Climate change. }\end{array}$ & $\begin{array}{l}\text { Maldives } \\
\text { Myanmar }\end{array}$ \\
\hline 13 & $\begin{array}{l}\text { CRITICAL RECORDS AND ADMINISTRATION. What other measures do you think are } \\
\text { missing from the above list of 'Community Support'? } \\
\text {-Incentives for staff to emergency response } \\
\text {-Establish data repository; Online data storage; Back-up of the LAN WAN; Disaster } \\
\text { management committee; Common chain of disaster management; Availability of Volunteer. } \\
\text {-Online banking }\end{array}$ & \\
\hline 15 & $\begin{array}{l}\text { COMMUNITY SUPPORT. What other measures do you think are missing from the above } \\
\text { list of 'Community Support'? } \\
\text {-Feedback mechanism on the improvement of conduct of drills; Assessment of access to } \\
\text { funds in terms of equal distribution to the communities; Assessment of quality of support } \\
\text { given to communities; } \\
\text {-Depend on site specific requirement; }\end{array}$ & Philippines \\
\hline 16 & $\begin{array}{l}\text { Any other comments on the Port Resilient Measures that you would like us to consider? } \\
\text {-Rehabilitation plan; Health care and psychological support; Establishment of the early } \\
\text { warning system in accordance with time stream; Understanding of the disaster for the } \\
\text { community to overcome the barriers; Type of potential hazards for different ports; Risk } \\
\text { allocation among private, public and shared group; Establishment of the combat groups for } \\
\text { different disasters. } \\
\text {-Depend on site specific requirement }\end{array}$ & \\
\hline
\end{tabular}

